\title{
HEMOTÓRAX ESPONTÁNEO EN PACIENTE CON SCHWANNOMA DE MEDIASTINO*
}

\author{
Drs. Fabián González V. ${ }^{1}$, Ricardo Zuleta S. ${ }^{1}$ \\ 1 Equipo de Cirugía de Tórax, Complejo Hospitalario San José. \\ Facultad de Medicina Universidad de Santiago. \\ Santiago, Chile.
}

\section{Abstract}

\section{Spontaneous hemothorax caused by a Schwannoma of the posterior mediastinum}

Background: Schwannomas are the most common neurogenic tumors of the posterior mediastinum. They are usually asymptomatic and the symptoms associated with them are chest pain, cough and dyspnea. Case report: We report a 36 years old female consulting in the emergency room due to sudden onset dyspnea. The imaging study confirmed the presence of a hemothorax secondary to a tumor of the posterior mediastinum, which was surgically excised. The pathological study reported a Schwannoma.

Key words: Schwannoma, mediastinum, hemothorax.

\section{Resumen}

Introducción: El mediastino es un área anatómica que contiene estructuras y células pluripotenciales que pueden originar distintos tumores. Los Schwannomas son los tumores neurogénicos más comunes del mediastino posterior, se caracterizan por tener un crecimiento lento. A menudo son asintomáticos y se diagnostican como hallazgos radiológicos. Cuando son sintomáticos, lo más común es que presenten dolor torácico, tos y disnea. El hemotórax es una rara forma de manifestación. Caso clínico: Se presenta en este trabajo el caso de una mujer de 36 años, que ingresa al servicio de urgencia por un cuadro de disnea súbita. El estudio por imágenes confirma el diagnóstico de hemotórax, secundario a un tumor de mediastino posterior, el cual requiere cirugía. Anatomía patológica corrobora el diagnóstico presuntivo de Swchannoma de mediastino posterior. Conclusión: La cirugía es necesaria para poder resecar completamente el tumor y en el Schwannoma benigno es curativa.

Palabras clave: Schwannoma, mediastino posterior, hemotórax.

\footnotetext{
Los autores declaran no tener conflicto de interés.

Correspondencia: Dr. Fabián González V.

fagonzav@uc.cl
}

*Recibido el 14 de octubre de 2013 y aceptado para publicación el 13 de marzo de 2014. 


\section{Caso clínico}

Paciente de 36 años de sexo femenino, sin antecedentes mórbidos previos, no fumadora. Ingresa al servicio de urgencia del Complejo Hospitalario San José, por un cuadro de dolor de parrilla costal izquierda y disnea súbita de $4 \mathrm{~h}$ de evolución, no refiere contusión en región torácica. $\mathrm{Al}$ ingreso PA $100 / 72$, FC 115 regular, $\mathrm{T}^{\circ} 36,8^{\circ} \mathrm{C}$, al examen pulmonar, murmullo abolido en $2 / 3$ del hemitórax izquierdo, con aumento de la matidez. Presenta un hematocrito de $24,7 \%$. Rx. de tórax concordante con hemotórax izquierdo (Figura 1).

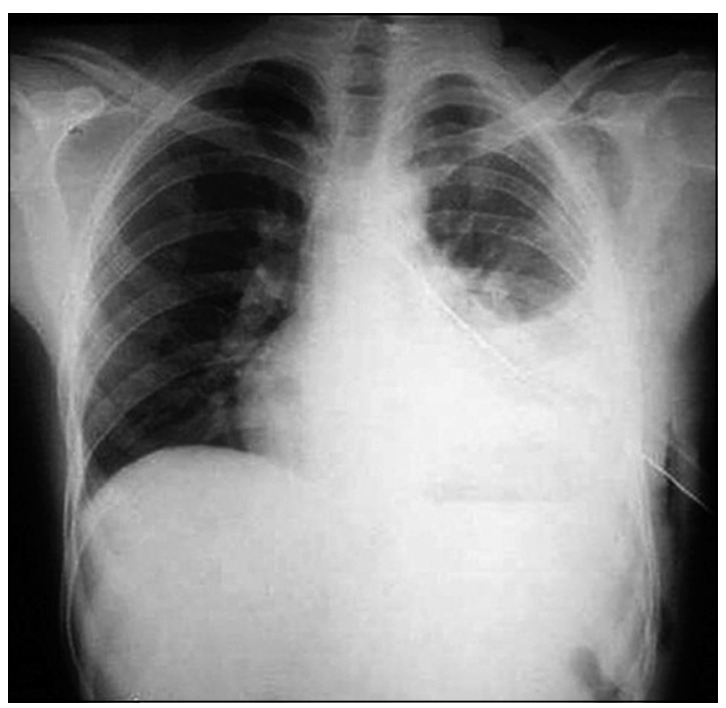

Figura 1. Hemotórax izquierdo.

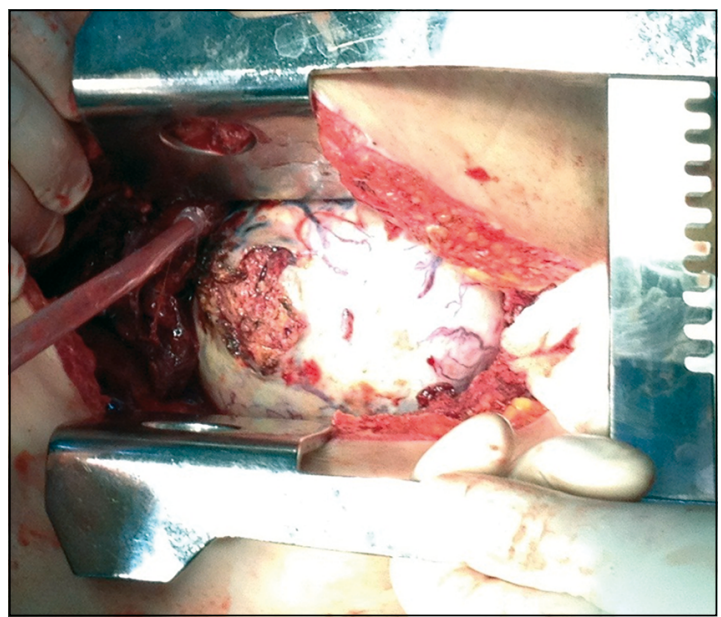

Figura 3. Tumor de mediastino posterior.
Se hospitaliza bajo el diagnóstico de hemotórax izquierdo espontáneo. Se transfunden 3 unidades de glóbulos rojos y se realiza pleurostomía, dando un débito de $1.100 \mathrm{cc}$ hemático por el tubo pleural. Debido a que la paciente se encuentra estable hemodinámicamente. Se realiza TC de tórax, que muestra, hemotórax organizado y masa en mediastino posterior izquierda de 14 x $18 \mathrm{~cm}$ (Figura 2).

Ingresa a pabellón para toracotomía postero lateral izquierda, que evidencia hemotórax organizado, además de masa muy vacularizada, descrita en TC. El pedículo vascular central, se origina de la aorta descendente (Figuras 3-4).

Se reseca masa tumoral ligando pedículo con prolene 0 . Paciente ingresa a UCI para manejo intensivo. Hemodinámicamente estable en ventilación mecánica sin requerimiento de drogas vasoactivas.

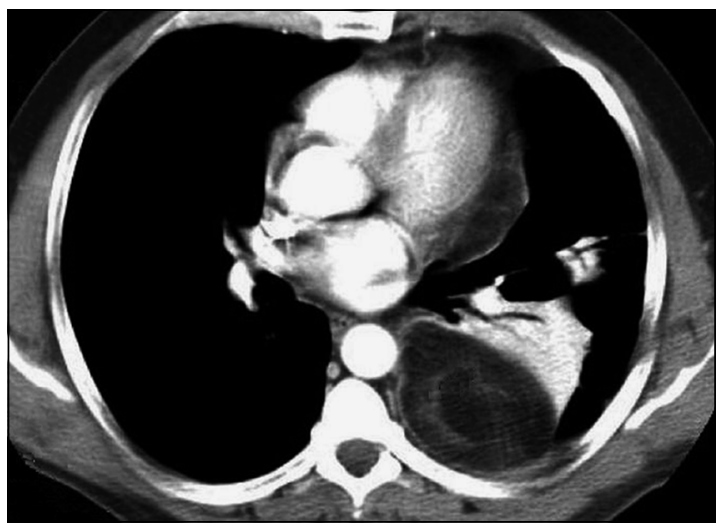

Figura 2. TC de Tórax que muestra hemotórax y masa mediastínica.

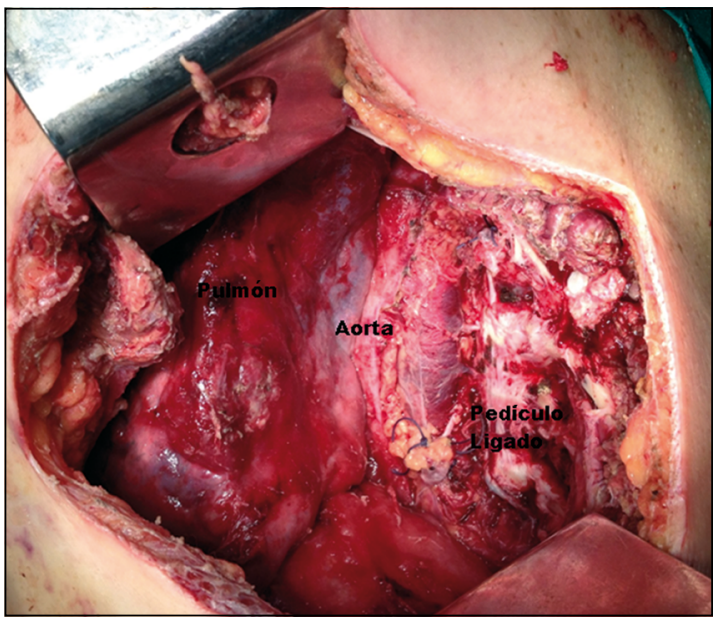

Figura 4. Mediastino posterior post resección del Swchanoma. 
Es extubada al $3^{\circ}$ día post operatorio, TC de tórax de control, sin alteraciones. Es trasladada a la UTI donde se retira pleurostomía. $\mathrm{Al} 7^{\circ}$ día se traslada al servicio de cirugía. Paciente en buenas condiciones generales sin dolor, hcto de control de $36 \%$, es dada de alta al día siguiente.

En control ambulatorio, la histopatología describe Swchannoma de mediastino posterior. Se decide control en 1 año con nuevo TC de tórax.

\section{Discusión}

El mediastino es un área anatómica que contiene estructuras y células pluripotenciales que pueden originar distintos tumores. La mayor parte de los tumores de nervio periféricos en el tórax son localizados en el mediastino posterior. Del 12 al 21\% corresponden a tumores neurogénicos ${ }^{1}$.

Los Schwannomas son los tumores neurogénicos más comunes, provienen de las células de Schwann. Se caracterizan por tener un crecimiento lento y generalmente se presentan como hallazgo durante un estudio radiográfico ${ }^{2}$. Frecuentemente se originan en la raíz de un nervio espinal y pueden involucrar el nervio torácico.

El riesgo de malignidad de estos tumores es muy pequeño, 2 a $5 \%$. La malignidad se sospecha por presencia de necrosis, pleomorfismo celular, invasión de tejidos adyacentes y elevada actividad mitótica. En nuestro caso, no se identificó ninguna de estas características.

Los Schwannomas generalmente son asintomáticos, pero debido a su crecimiento, dan síntomas cuando producen compresión local. Raras veces se manifiestan como hemotórax.
Morimoto et al y Lee et al, describen 7 casos de Schwannomas en mediastino que presentan hemotórax ${ }^{3,4}$.

La presencia de hemosiderina dentro del tumor sugiere que el hemotórax fue causado por una ruptura espontánea, de una zona de debilidad vascularizada del tumor ${ }^{4}$, provocando el sangrado. Esto descarta un traumatismo externo, cosa que la paciente afirma no haber presentado.

La toracotomía posterolateral es necesaria no sólo para el diagnóstico, sino para poder resecar completamente el tumor y liberar el pulmón atrapado. La resección quirúrgica completa en el Schwannoma benigno es curativa ${ }^{5}$.

\section{Referencias}

1. Albores O, Domínguez LM, Jiménez E, Ramírez M. Schwannomas mediastinales. Comunicación de casos y revisión de la literatura. Rev Inst Nal Enf Resp Mex. 2004; 17:256-60.

2. Sánchez J, Jurado A, Leone G, Mena I, Barredo R, Panchana G. Schwannoma benigno de mediastino posterior. Reporte de caso clínico. Oncol. (Quito). 1995;4:77-81.

3. Morimoto J, Nakajima T, Iizasa T, Ishikawa A, Nishimura H, Shingyouji M, et al. Successful resection of Schwannoma from an intercostal nerve causing bloody pleural effusion: report of a case. Surg Today 2011;41:989-91.

4. Lee MH, Graham AN, Nicholson AG, Pastorino U. Solitary cellular Schwannoma presenting with haemothorax. J R Soc Med. 1998;91:596-7.

5. Yamaguchi M, Yoshino I, Fukuyama S, Osoegawa A, Kameyama T, Tagawa T, et al. Surgical treatment of neurogenic tumors of the chest. Ann Thorac Cardiovasc Surg. 2004;10:148-51. 